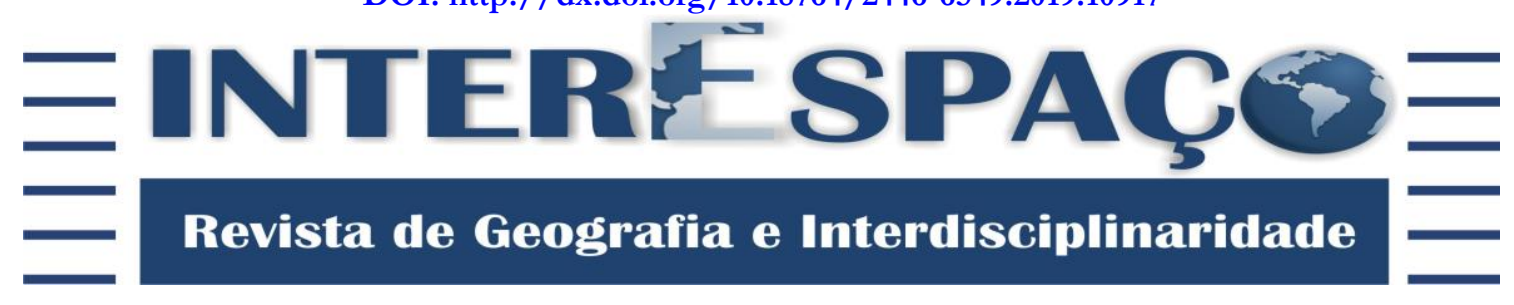

\title{
AS MULHERES NO PROGRAMA DE AQUISIÇÃO DE ALIMENTOS (PAA) NOS MUNICÍPIOS DE MIRANTE DO PARANAPANEMA E ROSANA (SP)
}

THE WOMEN IN THE PROGRAM OF FOOD ACQUISITION (PAA) IN THE
MUNICIPALITIES OF MIRANTE DO PARANAPANEMA AND ROSANA (SP)
LAS MUJERES EN EL PROGRAMA DE ADQUISICIÓN DE ALIMENTOS (PAA) EN LOS MUNICIPIOS DE MIRANTE DEL PARANAPANEMA Y ROSANA (SP)

\begin{abstract}
Eliane Regina Francisco da Silva
Doutora e Mestra em Geografia pela Universidade Estadual Paulista Júlio de Mesquita Filho UNESP/Presidente Prudente. lianecarvalho11@yahoo.com.br / http://orcid.org/0000-0002-6854-1431

Rosangela Aparecida de Medeiros Hespanhol

Doutora em Geografia pela Universidade Estadual Paulista Júlio de Mesquita Filho - UNESP/Rio Claro. Professora do Departamento de Geografia e do Programa de Pós-graduação em Geografia da UNESP/Presidente Prudente. rosangela.hespanhol@unesp.br / http://orcid.org/0000-0002-5073-8308
\end{abstract}

Recebido para avaliação em 24/02/2019; Aceito para publicação em 24/04/2019.

\section{RESUMO}

O objetivo deste artigo é analisar a participação das mulheres no Programa de Aquisição de Alimentos (PAA) nos municípios de Mirante do Paranapanema e Rosana (SP). Buscamos expor algumas características dos municípios em questão e, em especial, de que forma o programa tem contribuído para a conquista da autonomia das agricultoras familiares. Os procedimentos metodológicos utilizados foram a pesquisa de campo durante os meses de março e abril de 2016 nos municípios selecionados e o levantamento bibliográfico. Os resultados obtidos mostraram que o PAA tem contribuído para a autonomia socioeconômica das mulheres e para a valorização e visibilidade do trabalho destas na escala nacional.

Palavras-chave: PAA; Mulheres na Agricultura; Municípios de Mirante do Paranapanema e Rosana (SP).

\section{ABSTRACT}

The objective of this article is to analyze the participation of women in the Food Acquisition Program (PAA) in the municipalities of Mirante do Paranapanema and Rosana (SP). We seek to outline some characteristics of the municipalities in question and, in particular, how the program has contributed to the achievement of the autonomy of family farmers. The methodological procedures used were the field research during the months of March and April of 2016 in the selected municipalities and the bibliographic survey. The results showed that the PAA has contributed to the socioeconomic autonomy of women and to the valorization and visibility of their work.

Keywords: PAA; Women in Agriculture; Municipalities of Mirante do Paranapanema and Rosana (SP). 
|Eliane Regina Francisco da Silva | Rosangela Aparecida de Medeiros Hespanhol|

\section{RESUMEN}

El objetivo de este artículo es analizar la participación de las mujeres en el Programa de Adquisición de Alimentos (PAA) en los municipios de Mirante do Paranapanema y Rosana (SP). Buscamos exponer algunas características de los municipios en cuestión y, en especial de qué forma el programa ha contribuido a la conquista de la autonomía de las agricultoras familiares. Los procedimientos metodológicos utilizados fueron la investigación de campo durante los meses de marzo y abril de 2016 en los municipios seleccionados y el levantamiento bibliográfico. Los resultados obtenidos mostraron que el PAA ha contribuido a la autonomía socioeconómica de las mujeres ya la valorización y visibilidad del trabajo de éstas.

Palabras clave: PAA; Mujeres en la Agricultura; Municipios de Mirante do Paranapanema y Rosana (SP).

\section{INTRODUÇÃO}

Nessa pesquisa, dentre outros objetivos, buscamos estudar os benefícios e os impasses relacionados ao Programa de Aquisição de Alimentos (PAA) por meio da aplicação de entrevistas semiestruturadas junto a 32 famílias agricultoras do município de Mirante do Paranapanema (SP) e 16 famílias agricultoras do município de Rosana (SP). Para o desenvolvimento da pesquisa foram realizadas revisão bibliográfica e coleta e sistematização de dados e informações de fontes primárias e secundárias.

Quando entrevistamos as famílias foi possível perceber que o PAA está trazendo impactos relevantes no cotidiano das mulheres agricultoras, pois estas assumem todas as etapas da produção e comercialização agrícola. Essa realidade propicia reflexões interessantes sobre a questão do gênero na agricultura familiar e como as políticas públicas podem contribuir para a autonomia das agricultoras familiares.

O artigo encontra-se estruturado em três (3) partes, além desta introdução, das considerações finais e das referências bibliográficas. Na primeira parte discorremos sobre as características do Programa de Aquisição de Alimentos (PAA), na segunda parte fizemos algumas considerações sobre os municípios analisados e na terceira parte discutimos sobre a participação das mulheres no PAA em termos nacionais e no recorte espacial analisado.

\section{O PROGRAMA DE AQUISIÇÃO DE ALIMENTOS (PAA)}

O PAA foi criado como uma das ações estruturantes do Programa Fome Zero e foi instituído pelo artigo 19 da Lei $\mathrm{n}^{\circ}$. 10.696, de 2 de julho de 2003, sendo atualmente regulamentado pelo Decreto $\mathrm{n}^{\circ}$. 6.447, de 07 de maio de 2008. De acordo com Veloso (2011), o PAA foi implementado como um programa social que se mostrou como um importante instrumento de apoio à comercialização de parte da produção agropecuária dos 
|As mulheres no Programa de Aquisição de Alimentos (PAA) nos municípios de Mirante do Paranapanema e Rosana (SP)|

|Eliane Regina Francisco da Silva | Rosangela Aparecida de Medeiros Hespanhol|

agricultores familiares. Esse programa tem sido responsável pela geração de renda e incentivo e apoio aos agricultores que produzem gêneros alimentícios. Além disso, tem fomentado as formas coletivas de organização.

O PAA movimentou a posição dos envolvidos quanto as suas territorialidades ${ }^{1}$ por meio da comercialização, dando-lhes vantagens diferenciadas. E, dessa forma, passa a ser inegável o fato de que houve uma mudança considerável no campo brasileiro. O mercado institucional garantiu: um canal de comercialização alternativo aos atravessadores (intermediários), incentivou o associativismo e a agroecologia, dentre outros. Fomentando, desse modo, formas de poder diferenciadas que repercutem fundamentalmente na produção e na reprodução social dos agricultores familiares. Além disso, pode-se falar não apenas em contribuições materiais, mas também em contribuições subjetivas, principalmente porque estabelece uma nova forma de pensar o papel do Estado em garantir a compra de parte da produção dos agricultores familiares e, concomitantemente, a alimentação de um número significativo de pessoas em situação de vulnerabilidade alimentar e nutricional - se opondo assim, à política creditícia predominante até então (SOUZA, 2018).

De acordo com Marioto (2013), o PAA funciona calcado numa relação de ministérios, esferas administrativas estaduais e municipais e representantes da sociedade civil, bem como associações e cooperativas de produtores rurais que constituem arranjos institucionais que, por sua vez, são definidos por Frey (2000) como o resultado de negociações entre os agentes políticos, compreendendo os padrões de comportamento existentes e os esperados pelas instituições políticas envolvidas.

De acordo com o Ministério do Desenvolvimento Social (MDS), os beneficiários do PAA devem estar enquadrados no Cadastro Único para Programas Sociais do Governo Federal, também conhecido como Cadastro Único - que é uma ferramenta que identifica e caracteriza as famílias de baixa renda. São famílias de baixa renda aquelas que possuem meio salário mínimo mensal por pessoa integrante da mesma ou que a renda total mensal é de até três (3) salários mínimos. Nele são registradas várias informações, como por exemplo: características da residência, identificação de cada pessoa, escolaridade, situação de trabalho e renda, dentre outras. A partir de 2003, o Cadastro Único se tornou o principal instrumento do Estado brasileiro para a seleção e a inclusão de famílias de baixa

\footnotetext{
${ }^{1}$ Saquet (2010) afirma que territorialidade se refere às relações ocorridas no território e estão intrincadas aos processos sociais semelhantes e diferentes. A combinação específica e de cada relação espaço-tempo é produto que acompanha e condiciona os processos e configurações territoriais. $O$ autor salienta ainda que as relações de poder são múltiplas e com escalas diferenciadas, desse modo, em nosso cotidiano, presenciamos relações que são vividas, sentidas e às vezes compreendidas de formas distintas.
} 
|As mulheres no Programa de Aquisição de Alimentos (PAA) nos municípios de Mirante do Paranapanema e Rosana (SP)|

|Eliane Regina Francisco da Silva | Rosangela Aparecida de Medeiros Hespanhol|

renda em programas federais. Também pode ser utilizado para a seleção de beneficiários de programas oferecidos pelos governos estaduais e municipais, ou seja, funciona como uma "porta de entrada" para as famílias acessarem diversas políticas públicas. A execução do Cadastro Único é de responsabilidade compartilhada entre o governo federal, os estados, os municípios e o Distrito Federal. Na escala federal, o MDS é o gestor responsável, e a Caixa Econômica Federal é o agente operador que mantém o Sistema de Cadastro Único (BRASIL/MDS, 2014).

Os gêneros alimentícios produzidos pelos agricultores familiares no nosso recorte espacial de estudo são entregues no município de Mirante do Paranapanema (SP) e em seus distritos, Cuiabá Paulista e Costa Machado e os produzidos no município de Rosana (SP) são distribuídos no assentamento Gleba XV de Novembro e no município de Euclides da Cunha Paulista (SP).

\section{O RECORTE ESPACIAL DE ESTUDO}

O município de Mirante do Paranapanema (SP) está localizado no sudoeste do estado de São Paulo e está inserido na Microrregião Geográfica de Presidente Prudente. Tem como municípios limítrofes: Sandovalina, Presidente Bernardes, Santo Anastácio, Marabá Paulista e Teodoro Sampaio (Mapa 1). O avanço dos trilhos da Estrada de Ferro Sorocabana, que objetivavam atingir as barrancas do Rio Paraná, trouxe os primeiros exploradores de parte do Oeste Paulista, favorecendo o surgimento de vários núcleos populacionais (RAMALHO, 2002), como no caso do município de Mirante do Paranapanema (SP).

Segundo Santos (2003), a história de Mirante do Paranapanema está intimamente relacionada aos episódios ocorridos com a questão da posse e o processo intensivo de grilagem das terras ${ }^{2}$.

\footnotetext{
2 Tem-se por grilagem de terras o processo de falsificação de documentos das propriedades fundiárias. O termo se refere à técnica de se envelhecer papéis utilizando grilos, ou seja, esses insetos são trancados em gavetas até que morram para a liberação de resinas que mancham os papéis e os deixam com aspecto de velho (FERNANDES, 2003).
} 
|As mulheres no Programa de Aquisição de Alimentos (PAA) nos municípios de Mirante do Paranapanema e Rosana (SP)|

|Eliane Regina Francisco da Silva | Rosangela Aparecida de Medeiros Hespanhol|

Mapa 1 - Localização dos municípios de Mirante do Paranapanema e Rosana (SP) na Microrregião Geográfica de Presidente Prudente, Estado de São Paulo
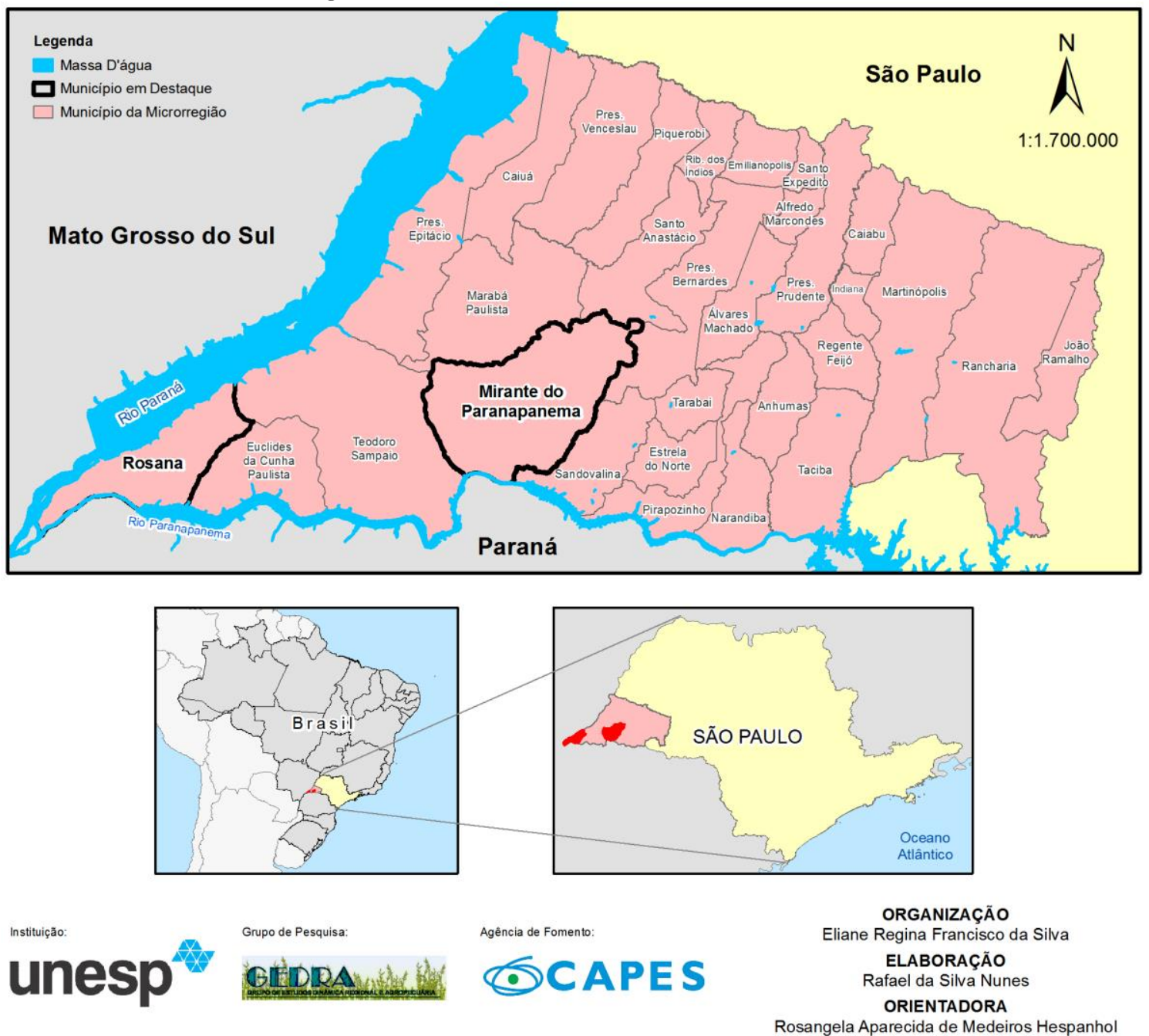

Fonte: Organizado e elaborado por Eliane Regina Francisco da Silva e Rafael da Silva Nunes.

Os dados da Tabela 1 mostram que o município de Mirante de Paranapanema (SP), tal qual a Microrregião Geográfica (MRG) de Presidente Prudente, apresenta concentração da estrutura fundiária, pois 59.192 hectares ou 61\% do total de grupo de área $(97.010$ hectares) correspondem às áreas de grandes estabelecimentos no ano de 1995/96. No ano de 2006, 33.923 hectares ou 35,02\% do total do grupo de área (96.856 hectares) se referem aos grandes estabelecimentos. 
|As mulheres no Programa de Aquisição de Alimentos (PAA) nos municípios de Mirante do Paranapanema e Rosana (SP)|

|Eliane Regina Francisco da Silva | Rosangela Aparecida de Medeiros Hespanhol|

Tabela 1 - Estrutura fundiária do município de Mirante do Paranapanema (1995/96 -2006)

\begin{tabular}{c|c|c|c|c|c|c|c|c}
\hline Anos & \multicolumn{7}{|c|}{$\mathbf{1 9 9 5 / 9 6}$} & \multicolumn{5}{c}{$\mathbf{2 0 0 6}$} \\
\hline Área (ha) & E. A.* & $\%$ & Área & $\%$ & E. A.* & $\%$ & Área & $\%$ \\
\hline Menos de 10 & 547 & 37,2 & 3.455 & 5,83 & 343 & 15,04 & 1.834 & 2,59 \\
\hline $\begin{array}{c}\text { De 10 a menos de } \\
50\end{array}$ & 613 & 41,67 & 3.124 & 5,27 & 1.662 & 72,89 & 11.942 & 16,88 \\
\hline $\begin{array}{c}\text { De 50 a menos de } \\
100\end{array}$ & 121 & 8,22 & 9.913 & 16,73 & 128 & 5,61 & 21.560 & 30,47 \\
\hline $\begin{array}{c}\text { De 100 a menos } \\
\text { de 500 }\end{array}$ & 157 & 10,67 & 8.653 & 14,60 & 124 & 5,43 & 9.159 & 12,94 \\
\hline $\begin{array}{c}\text { De 500 a menos } \\
\text { de 1.000 }\end{array}$ & 20 & 1,36 & 11.617 & 19,60 & 18 & 0,79 & 9.687 & 13,69 \\
\hline Mais de 1.000 & 13 & 0,88 & 22.507 & 37,97 & 5 & 0,22 & 16.580 & 23,43 \\
\hline Total & 1471 & 100 & 59.269 & 100 & 2.280 & 100 & 70.762 & 100 \\
\hline \multicolumn{7}{c|}{ E. A.*: Estabelecimentos Agropecuários. }
\end{tabular}

Fonte: IBGE - Censos Agropecuários de 1995/96 e 2006.

Resumidamente, no ano de 1995/96, os estabelecimentos agropecuários com menos de 100 hectares no município de Mirante do Paranapanema (SP) somavam 1.281, contabilizando 87,09\% do total, correspondendo, a uma área ocupada de 16.492 hectares, ou $27,83 \%$ da área total. Os estabelecimentos agropecuários do estrato de 100 a menos de 500 hectares contabilizam 157, numa área de 8.653 hectares enquanto que os estabelecimentos agropecuários com mais de 500 hectares totalizavam 33, numa área de 34.124 hectares. Comparando o ano de 1995/96 com o de 2006, os estabelecimentos agropecuários com menos de 100 hectares obtiveram aumento de um total de 852, enquanto que os do estrato de 100 a menos de 500 hectares tiveram uma diminuição de 33. Já os estabelecimentos agropecuários com mais de 500 hectares tiveram um decréscimo de 10 entre 1995/96 e 2006 (Tabela 1).

Em termos gerais, houve um aumento no número de pequenos estabelecimentos agropecuários e uma modesta diminuição no total dos grandes em decorrência da implantação de assentamentos rurais.

De acordo com os dados da Tabela 2, verificou-se que em termos gerais, de 1991 a 2000 houve uma variação populacional de 6,75\%, enquanto que de 2000 a 2010, a variação populacional foi de 5,31\%. Em outros termos, em 1991 a população rural do município de Mirante do Paranapanema (SP) era de 4.634 habitantes e em 2010, já era de 7.017 habitantes. A população urbana, em 1991, era de 10.545 habitantes e em 2010 era de 10.047. Esse fato está correlacionado, ao menos parcialmente, à implantação de assentamentos rurais no município em apreço. 
|As mulheres no Programa de Aquisição de Alimentos (PAA) nos municípios de Mirante do Paranapanema e Rosana (SP)|

|Eliane Regina Francisco da Silva | Rosangela Aparecida de Medeiros Hespanhol|

Tabela 2 - Dinâmica populacional do município de Mirante do Paranapanema (1991-2010)

\begin{tabular}{|c|c|c|c|c|c|c|c|}
\hline Anos & $\begin{array}{c}\text { População } \\
\text { Total }\end{array}$ & $\begin{array}{c}\text { População } \\
\text { Rural }\end{array}$ & $\begin{array}{c}\text { População } \\
\text { rural } \\
(\%)\end{array}$ & $\begin{array}{c}\text { População } \\
\text { urbana }\end{array}$ & $\begin{array}{c}\text { População } \\
\text { urbana } \\
(\%)\end{array}$ & $\begin{array}{c}\text { Variação } \\
\text { da } \\
\text { População } \\
\text { Total } \\
(1991 \text { a } \\
2000 \text { e de } \\
2000 \text { a } \\
2010)\end{array}$ & $\begin{array}{c}\text { Variação } \\
\text { da } \\
\text { População } \\
\text { Total } \\
(1991 \text { a } \\
2000 \text { e de } \\
2000 \text { a } \\
2010) \\
(\%)\end{array}$ \\
\hline 1991 & 15.179 & 4.634 & 30,53 & 10.545 & 69,47 & 1.024 & 6,75 \\
\hline 2000 & 16.203 & 6.347 & 39,35 & 9.827 & 60,65 & & \\
\hline 2010 & 17.064 & 7.017 & 41,12 & 10.047 & 58,88 & 861 & 5,31 \\
\hline
\end{tabular}

De acordo com o IBGE (2018), a população do município de Mirante do Paranapanema (SP) foi estimada, em 2017, em 18.130 habitantes.

Foram verificadas alterações positivas no IDHM do município de Mirante do Paranapanema (SP) no período de 1991 a 2010. Em 1991, o referido índice era de 0,496, em 2000 era de 0,630, já em 2010 era de 0,724 (BRASIL/PLATAFORMA ATLAS BRASIL, 2018).

De acordo com a Plataforma Atlas Brasil (2018), o município de Mirante do Paranapanema (SP) se situa na faixa de Desenvolvimento Humano Alto (IDHM entre 0,700 e 0,799) e a dimensão que mais contribui para o IDHM do município é Longevidade, com índice de 0,841, seguida de Educação, com índice de 0,674, e de Renda, com índice de 0,670. O referido município ocupa a $1.191^{\text {a }}$ posição entre os 5.565 municípios brasileiros segundo o IDHM.

O município de Mirante do Paranapanema (SP) é considerado “a capital da Reforma Agrária" por conta do seu expressivo número de assentamentos rurais (35 no total) com 1.631 famílias assentadas, segundo o Plano Municipal de Desenvolvimento Rural Sustentável - PMDRS (2015) de Mirante do Paranapanema (SP).

O município de Rosana (SP), por sua vez, está localizado no extremo oeste do estado de São Paulo e pertencente à Microrregião Geográfica de Presidente Prudente. Têm como limites os municípios de Teodoro Sampaio (SP), Euclides da Cunha Paulista (SP), Diamante do Norte (PR), Bataiporã (MS) e Anaurilândia (MS) (Mapa 1). De acordo com Souza (2007), a formação socioeconômica do município de Rosana (SP) está relacionada com a expansão da cafeicultura; a implantação da estrada de Ferro Alta Sorocabana, sobretudo com a ampliação do Ramal de Dourados; com as rodovias e os projetos de desenvolvimento do Pontal do Paranapanema que propiciaram a construção de usinas hidrelétricas e de destilaria de álcool nessa região. 
|As mulheres no Programa de Aquisição de Alimentos (PAA) nos municípios de Mirante do Paranapanema e Rosana (SP)|

|Eliane Regina Francisco da Silva | Rosangela Aparecida de Medeiros Hespanhol|

Levando-se em conta os dados da Tabela 3, verifica-se que, assim como na Microrregião Geográfica (MRG) de Presidente Prudente, de um modo geral, no município de Rosana (SP) há concentração da estrutura fundiária, pois 32.836 hectares ou $74,7 \%$ do total de grupo de área (44.672 hectares) correspondem às áreas de grandes estabelecimentos no ano de 1995/96. Já no ano de 2006, 43.076 hectares ou 77,3\% do total do grupo de área (55.761 hectares) se referem aos grandes estabelecimentos.

Tabela 3 - Estrutura fundiária do município de Rosana (1995/96 -2006)

\begin{tabular}{c|c|c|c|c|c|c|c|c}
\hline Anos & \multicolumn{3}{|c|}{$\mathbf{1 9 9 5 / 9 6}$} & \multicolumn{4}{c}{$\mathbf{2 0 0 6}$} \\
\hline Área (ha) & E. A.* & $\%$ & Área & $\%$ & E. A.* & $\%$ & Área & $\%$ \\
\hline Menos de 10 & 66 & 10,95 & 302 & 0,67 & 239 & 29,43 & 965 & 1,69 \\
\hline $\begin{array}{c}\text { De } 10 \text { a menos } \\
\text { de } 50\end{array}$ & 481 & 79,77 & 8.772 & 19,64 & 513 & 63,18 & 9.111 & 15,95 \\
\hline $\begin{array}{c}\text { De } 50 \text { a menos } \\
\text { de } 100\end{array}$ & 19 & 3,15 & 1.398 & 3,13 & 11 & 1,35 & 769 & 1,34 \\
\hline $\begin{array}{c}\text { De 100 a menos } \\
\text { de } 500\end{array}$ & 22 & 3,65 & 5.751 & 12,87 & 33 & 4,06 & 9.498 & 16,63 \\
\hline $\begin{array}{c}\text { De 500 a menos } \\
\text { de } 1.000\end{array}$ & 8 & 1,33 & 4.873 & 10,90 & 5 & 0,62 & 3.207 & 5,61 \\
\hline Mais de 1.000 & 7 & 1,16 & 23.572 & 52,7 & 11 & 1,35 & 33.578 & 58,78 \\
\hline Total & 603 & 100 & 44.668 & 100 & 812 & 100 & 57.128 & 100 \\
\hline \multicolumn{7}{c|}{ E. A.*: Estabelecimentos Agropecuários. }
\end{tabular}

Fonte: IBGE - Censos Agropecuários de 1995/96 e 2006.

Em suma, na Tabela 3 foi verificado que no município de Rosana (SP), no período de 1995/96 a 2006, houve um aumento de 197 estabelecimentos agropecuários com menos de 100 hectares. Os estabelecimentos agropecuários do estrato de 100 a menos de 500 hectares tiveram aumento de 11 no mesmo período, enquanto que os estabelecimentos agropecuários com mais de 500 hectares apresentaram aumento de um (1) estabelecimento. Vale ressaltar que os estabelecimentos agropecuários com mais de 1.000 hectares que em 1995/96 somavam sete (7), numa área ocupada de 23,572 hectares ou 1,16\% do total, em 2006, aumentaram para 11, ocupando 33.578 hectares ou 58,78 da área total.

A população rural do município de Rosana (SP) no ano de 2000 era quase o triplo da urbana, enquanto que em 2010, a população urbana já era quase cinco (5) vezes maior que a rural (Tabela 4). 
|As mulheres no Programa de Aquisição de Alimentos (PAA) nos municípios de Mirante do Paranapanema e Rosana (SP)|

|Eliane Regina Francisco da Silva | Rosangela Aparecida de Medeiros Hespanhol|

Tabela 4 - Dinâmica populacional do município de Rosana (2000-2010)

\begin{tabular}{c|c|c|c|c|c|c|c}
\hline \multirow{2}{*}{ Anos } & $\begin{array}{c}\text { População } \\
\text { Total }\end{array}$ & $\begin{array}{c}\text { População } \\
\text { Rural }\end{array}$ & $\begin{array}{c}\text { População } \\
\text { rural } \\
\mathbf{( \% )}\end{array}$ & $\begin{array}{c}\text { População } \\
\text { Urbana }\end{array}$ & $\begin{array}{c}\text { População } \\
\text { urbana } \\
\mathbf{( \% )}\end{array}$ & $\begin{array}{c}\text { Variação } \\
\text { da } \\
\text { População } \\
\text { Total } \\
\mathbf{( 2 0 0 0 -} \\
\mathbf{2 0 1 0}\end{array}$ & $\begin{array}{c}\text { Variação } \\
\text { da } \\
\text { População } \\
\text { Total } \\
\mathbf{( 2 0 0 0 - 2 0 1 0 )} \\
\mathbf{( \% )}\end{array}$ \\
\hline 2000 & 24.192 & 18.003 & 74,42 & 6.198 & 25,58 & -4501 & $-18,61$ \\
\hline 2010 & 19.691 & 3.833 & 19,47 & 15.858 & 80,53 & & \\
\hline
\end{tabular}

Fonte: FIBGE - Censos Demográficos de 2000 e 2010.

De um modo geral, houve um decréscimo do contingente populacional do município de Rosana (SP) no período de 2000 a 2010 de 4.501 habitantes ou de 18,61\% (Tabela 4). Vale lembrar que a conclusão da construção da Usina Hidrelétrica Sérgio Motta no ano de 1999, com a dispensa de grande número de trabalhadores, contribuiu para a diminuição da população do município de Rosana (SP).

Segundo o IBGE (2018), a população do município de Rosana (SP) foi estimada no ano de 2017 em 17.795 habitantes.

Quanto ao Índice de Desenvolvimento Humano (IDHM) do município de Rosana (SP) verificaram-se alterações positivas de 0,540, em 1991, para 0,688 em 2000 e para 0,764 no ano de 2010 (BRASIL/PLATAFORMA ATLAS BRASIL, 2018).

Segundo a Plataforma Atlas Brasil (2018), o município de Rosana (SP) se situa na faixa de Desenvolvimento Humano Alto (IDHM entre 0,700 e 0,799) e a dimensão que mais contribui para o IDHM do município é Longevidade, com índice de 0,818, seguida de Renda, com índice de 0,749, e de Educação, com índice de 0,728. O referido município ocupa a $304^{a}$ posição entre os 5.565 municípios brasileiros segundo o IDHM.

Apesar dos dados apresentados por meio das consultas no SEADE e na Plataforma Atlas Brasil mostrarem que, estatisticamente, o desenvolvimento humano no município de Rosana (SP) é maior que no município de Mirante do Paranapanema (SP), Silva (2011, p. 97) adverte que:

\footnotetext{
Determinada cidade pequena da região de Presidente Prudente pode ter um grande PIB como ocorre com Rosana, em razão dos royalties pagos pelo Estado dado o impacto da Usina Hidrelétrica Engenheiro Sérgio Motta (instalada em seu território), mas possuir uma população pobre e uma estrutura de serviços com caráter deficitário, bem como acumular diversos escândalos de corrupção em algumas de suas gestões municipais (em termos de má administração com afastamento de prefeitos).
}

Na prática, os altos valores do PIB apresentados por determinados municípios, como no caso em análise, Rosana (SP), não significam efetivamente melhor distribuição de renda e desenvolvimento humano para a população desta localidade em virtude de que o PIB demonstra apenas o montante do dinheiro usado e não a qualidade desse uso, ou seja, 
|As mulheres no Programa de Aquisição de Alimentos (PAA) nos municípios de Mirante do Paranapanema e Rosana (SP)|

|Eliane Regina Francisco da Silva | Rosangela Aparecida de Medeiros Hespanhol| se propiciou ou não melhores condições de vida que incluem infraestrutura, saúde, educação, dentre outros.

O município de Rosana (SP) possui 4 assentamentos rurais com 628 famílias assentadas, segundo o Plano Municipal de Desenvolvimento Rural Sustentável - PMDRS (2015) de Rosana (SP).

A justificativa para a escolha do estudo desse tema em Mirante do Paranapanema e Rosana (SP) pauta-se no fato de que, enquanto o primeiro município citado teve o maior número de associações de produtores (nove) e os maiores valores de projetos aprovados no PAA, ou seja, R $\$ 2.496 .000,00$, em 2015, o segundo município teve o menor número de associações de produtores (uma) e os menores valores dos projetos aprovados no PAA, a saber, R\$128.000,00, em 2015, dentre os municípios da MRG de Presidente Prudente, de acordo com informações disponibilizadas no site da Companhia Nacional de Abastecimento (CONAB). Consideramos também na seleção dos municípios pesquisados, o fato de ambos possuírem assentamentos rurais em seu território, o que nos possibilita ter condições de confrontar os resultados obtidos por meio da pesquisa de campo.

\section{MULHERES NO PAA: o caso das agricultoras familiares dos municípios de Mirante do Paranapanema e Rosana (SP)}

A partir de 2011, os projetos para acessar o PAA tiveram como um dos requisitos de aprovação a exigência de participação mínima de 40\% de mulheres como beneficiárias fornecedoras na modalidade CDS e 30\% na modalidade CPR Estoque, de acordo com a Resolução no 44 de 16 de agosto de 2011, do GGPAA (BRASIL/CONAB, 2015).

A participação ativa das mulheres não somente na produção, mas também em outras etapas da atividade agrícola, como a colheita, a comercialização, mesmo que de maneira modesta, suscita vários benefícios a elas, a saber: o aumento da renda e a autonomia econômica. A autonomia econômica, por sua vez, é fundamental, pois tendo seu próprio dinheiro, a mulher não se encontra mais tão submissa ao homem, o que lhe permite adquirir seus objetos pessoais sem precisar de autorização do esposo, "o que é considerado por muitas mulheres como constrangedor e humilhante. Por essa razão é importante para as mulheres que seu trabalho tenha uma remuneração específica, separada da do homem" (COUTINHO DE PAULA; HESPANHOL, 2012, p. 17).

Conforme se observa na Figura 1, a participação feminina nas modalidades do PAA na escala nacional alcançou em 2015 um contingente de 49\% e, em 2016, 57\%, reforçando a valorização de sua mão de obra, o aumento da renda e a garantia de sua inserção 
|As mulheres no Programa de Aquisição de Alimentos (PAA) nos municípios de Mirante do Paranapanema e Rosana (SP)|

|Eliane Regina Francisco da Silva | Rosangela Aparecida de Medeiros Hespanhol|

socioeconômica, minimizando, desse modo, a invisibilidade do papel da mulher no espaço rural (BRASIL. CONAB, 2015). Verifica-se que a participação feminina nas modalidades do PAA alcançou 71\% em 2017.

Figura 1 - Participação das mulheres no PAA de 2009 a 2017 na escala nacional

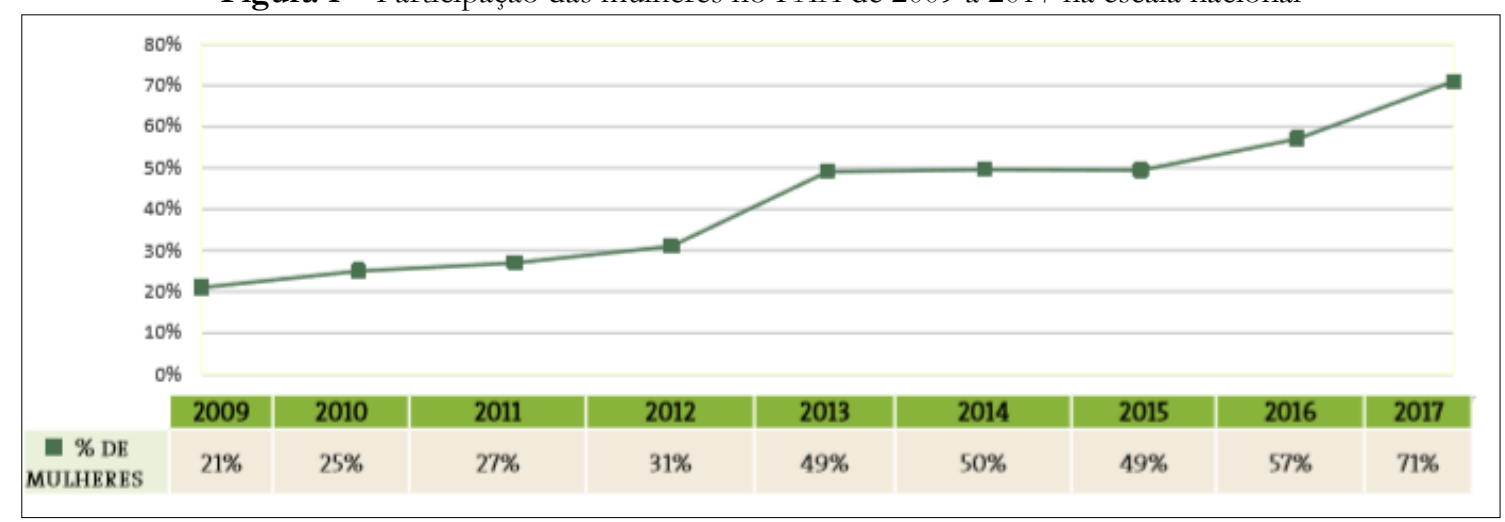

Fonte: BRASIL. CONAB (2018). SUPAF/GECAF.

Cabe ressaltar que o fortalecimento do trabalho e renda das mulheres no campo implica também na consolidação da segurança alimentar de suas famílias, uma vez que "são elas as principais responsáveis pela manutenção da unidade familiar, assumindo o controle pelos hábitos alimentares da família” (GOMES JÚNIOR; ANDRADE, 2013, p. 398).

$\mathrm{Na}$ Tabela 5 tem-se o número de produtores participantes do PAA nos municípios de Mirante do Paranapanema e Rosana (SP) no ano de 2015 e o tamanho da amostra de pesquisados.

Tabela 5 - Número de produtores participantes do PAA nos municípios de Mirante do Paranapanema e Rosana (SP) no ano de 2015 e tamanho da amostra de pesquisados

\begin{tabular}{c|c|c}
\hline Município & $\begin{array}{c}\text { Produtores } \\
\text { participantes } \\
\text { do PAA, } \\
\text { segundo a } \\
\text { CONAB }\end{array}$ & $\begin{array}{c}\text { Amostra de 10\% } \\
\text { dos produtores } \\
\text { participantes do } \\
\text { PAA que foram } \\
\text { pesquisados }\end{array}$ \\
\hline $\begin{array}{c}\text { Mirante do } \\
\text { Paranapanema }\end{array}$ & 312 & 32 \\
\hline Rosana & 16 & $16^{3}$ \\
\hline Total & 328 & 48 \\
\hline
\end{tabular}

Org. Eliane Regina Francisco da Silva (2015).

Fonte: BRASIL. CONAB (2015) e prefeituras municipais.

Tanto os 32 chefes de família analisados do município de Mirante do Paranapanema (SP) quanto os 16 chefes de família entrevistados do município de Rosana

\footnotetext{
3 Em virtude do baixo número de produtores cadastrados nesse município realizamos a aplicação de formulários a $100 \%$ deles e não somente a $10 \%$.
} 
|As mulheres no Programa de Aquisição de Alimentos (PAA) nos municípios de Mirante do Paranapanema e Rosana (SP)|

|Eliane Regina Francisco da Silva | Rosangela Aparecida de Medeiros Hespanhol|

(SP) disseram haver a participação das mulheres no desenvolvimento das atividades voltadas à produção e comercialização para entrega ao PAA (Figuras 2 e 3).

Figura 2 - Agricultora familiar do município de Mirante do Paranapanema (SP) trabalhando nas atividades

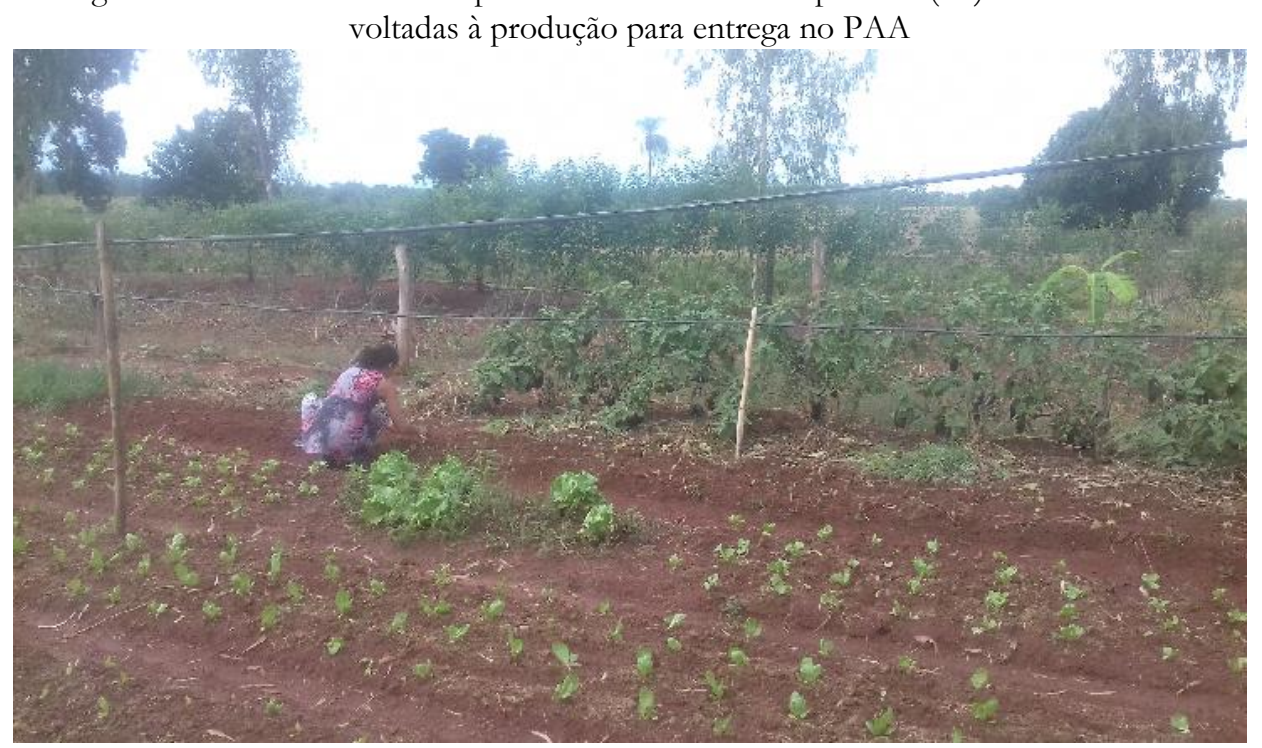

Fonte: Pesquisa de campo (março/2016).

Figura 3 - Agricultora familiar do município de Rosana (SP) trabalhando nas atividades voltadas à produção para entrega no PAA

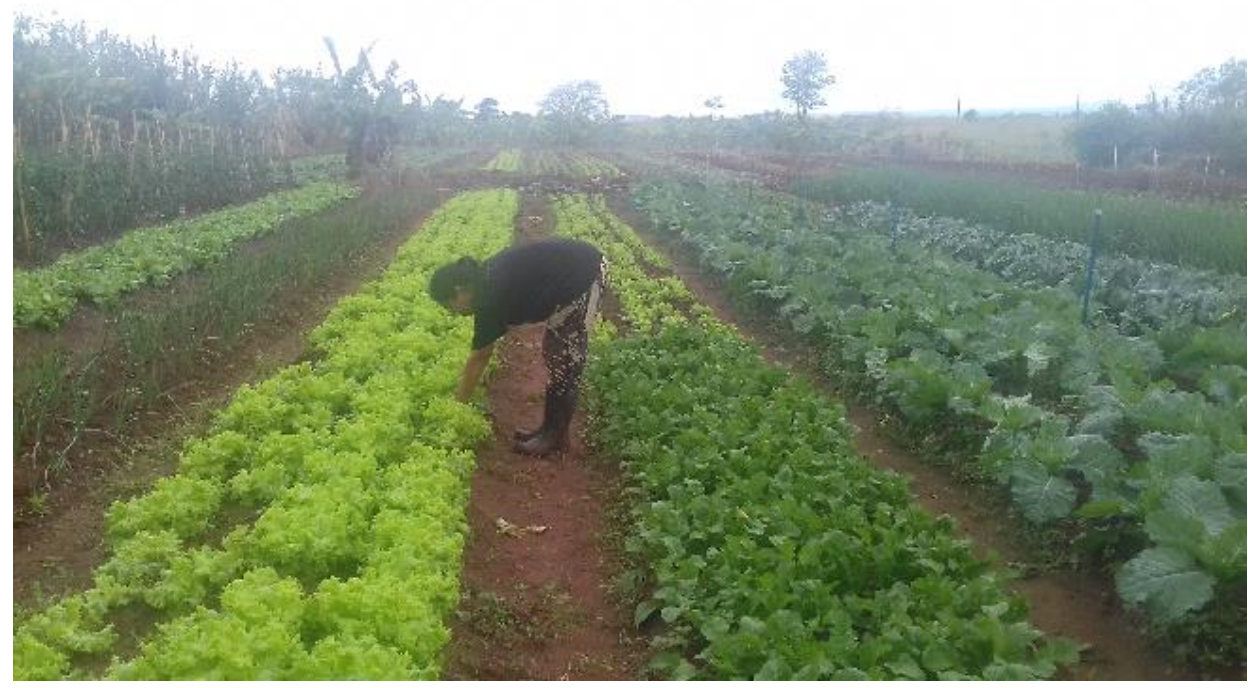

Fonte: Pesquisa de campo (abril/2016).

Vale ressaltar que a participação das mulheres no PAA nos municípios de Mirante do Paranapanema e Rosana (SP) não se restringia apenas no manejo produtivo dos gêneros alimentícios, mas também na comercialização destes.

Izidoro (2015, p. 68), ao estudar o PAA no município de Presidente Venceslau (SP) sob a perspectiva do gênero, infere que: 
|As mulheres no Programa de Aquisição de Alimentos (PAA) nos municípios de Mirante do Paranapanema e Rosana (SP)|

|Eliane Regina Francisco da Silva | Rosangela Aparecida de Medeiros Hespanhol|

É difícil para nós sinalizar se o aumento da participação das mulheres foi uma prática forçada pela resolução $\mathrm{n}^{\circ} 44$ emitida pela $\mathrm{SESAN}^{4}$ e, portanto, conveniente para a comunidade rural no sentido econômico, ou se partiu de uma superação orgânica do machismo nos assentamentos estudados.

A autora afirma ainda que "a separação espacial entre casa-quintal e roça-pasto passa a ser questionada, na medida em que, com a produção para o PAA, os espaços produtivo-comercial e o de reprodução social (casa e quintal) tendem a se confundir cada vez mais" (IZIDORO, 2015, p. 69).

Em outros termos, ao menos teoricamente, o trabalho desempenhado pelas mulheres passa a ter maior visibilidade e sua atuação maior protagonismo, pois as atividades tidas - na visão machista - como, exclusivamente, de responsabilidade da mulher, são fontes de consumo, mas também de renda familiar. Isso significou um avanço no tocante ao reconhecimento do trabalho das mulheres e ao mesmo tempo melhora das condições de vida dessas mulheres e da família.

No contexto oficial, o Ministério do Desenvolvimento Agrário (MDA), através da cartilha denominada "Políticas públicas para mulheres rurais no Brasil”, publicada em 2017, mostrou por meio de dados dos Censos Agropecuário de 2006 e Demográfico de 2010 que: i) 24,8\% das mulheres são responsáveis por famílias (únicas ou conviventes) (CENSO, 2010); ii) 34,1\% das mulheres com 16 anos ou mais que não possuem rendimento estão no meio rural (CENSO, 2010); iii) a razão entre o rendimento médio das mulheres ocupadas em relação ao dos homens ocupados no meio rural é 72,7\% (CENSO, 2010); iv) mulheres rurais contribuem com 42,4\% do rendimento familiar (CENSO, 2010); v) 12,68\% dos estabelecimentos têm como responsáveis as mulheres (CENSO AGRO, 2006); vi) 16\% dos estabelecimentos da Agricultura Familiar têm como responsáveis as mulheres (CENSO AGRO, 2006). O documento mostrou ainda que as mulheres rurais têm relevante papel na agricultura familiar, pois são responsáveis, em grande parte, pela produção destinada ao autoconsumo familiar e pelas práticas agroecológicas e de reprodução de sementes crioulas, garantindo qualidade de vida na família e na sociedade e manejo ambiental adequado às unidades de produção familiares. São mais de 14 milhões de mulheres no meio rural, representando 48\% da população destas áreas (BRASIL/MDA, 2017).

Izidoro (2015) afirma que um número mais expressivo de mulheres cadastradas no PAA evidencia que este programa tem abrangido os espaços que, culturalmente, foram

\footnotetext{
${ }^{4}$ A Secretaria de Segurança Alimentar e Nutricional (SESAN) é um dos órgãos públicos responsável pela gestão do PAA em conjunto com outros ministérios. A resolução $n^{\circ} 44$ admite que há uma desigualdade de acesso das mulheres ao programa e considera que uma maior geração de renda significaria uma maior autonomia econômica para estas. No documento evidencia-se o objetivo da resolução de fomentar o acesso de mulheres ao PAA. Ele reconhece o Estado como principal agente no combate às desigualdades de gênero no espaço produtivo (IZIDORO, 2015).
} 
|As mulheres no Programa de Aquisição de Alimentos (PAA) nos municípios de Mirante do Paranapanema e Rosana (SP)|

|Eliane Regina Francisco da Silva | Rosangela Aparecida de Medeiros Hespanhol|

associados ao trabalho das mulheres e que, por não gerarem renda monetária até então, tinham sua relevância secundarizada. A autora lembra que, ainda que o PAA tenha suas restrições e entraves, ele garantiu, por meio da compra daquilo que a mulher produz, uma reversão dessa visão machista. Antes invisível, o trabalho das mulheres desempenhado nas atividades mais comerciais realizadas no lote familiar, torna-se evidente, na medida em que o programa, sobretudo na modalidade Doação Simultânea, compra produtos agrícolas que, por serem anteriormente utilizados só para o autoconsumo, tinham seu cultivo sob responsabilidade principalmente das mulheres, como por exemplo, a horticultura.

As mulheres assumem um papel relevante não só no ato de cozinhar, mas na responsabilidade que têm tanto no cultivo destinado à participação no mercado aberto a elas por meio das políticas públicas, como por exemplo, o PAA, quanto no cultivo destinado à nutrição das suas famílias. Seus atos também representam grande importância na construção da soberania alimentar ${ }^{5}$ do país (GOMES JÚNIOR; ANDRADE, 2013).

Ressalta-se que houve aumento da participação feminina, mas a renda média anual foi oscilante no período de 2009 a 2017, conforme observado na Figura 4. Em 2015, a renda média obtida foi de $\mathrm{R} \$ 4.795,51$, já em 2016 o valor pago pelas aquisições dos produtos ficou em $\mathrm{R} \$ 4.072,85$, um déficit de aproximadamente 15,06\% (BRASIL. CONAB, 2015).

\footnotetext{
${ }^{5}$ Conforme Gomes Júnior e Andrade (2013, p. 393), a soberania alimentar “[...] trata a perspectiva do direito de populações - principalmente daquelas que tiram da relação com a terra o seu sustento - assegurarem o seu consumo com base na sua produção. Soberania alimentar torna-se um conceito elementar para articular a luta dos povos em defesa da alimentação como um bem e um valor cultural em oposição ao seu valor como mercadoria para atender aos interesses do mercado externo. Nesse contexto é que as mulheres trabalhadoras do campo exerceriam um papel decisivo, uma vez que toca a elas, principalmente, a provisão da casa e as lides associadas à produção diversificada dos alimentos que vão à mesa da família".
} 
|As mulheres no Programa de Aquisição de Alimentos (PAA) nos municípios de Mirante do Paranapanema e Rosana (SP)|

|Eliane Regina Francisco da Silva | Rosangela Aparecida de Medeiros Hespanhol|

Figura 4 - Renda média anual das mulheres no PAA, de 2009 a $2017^{6}$, em reais $(\mathrm{R} \$)^{7}$

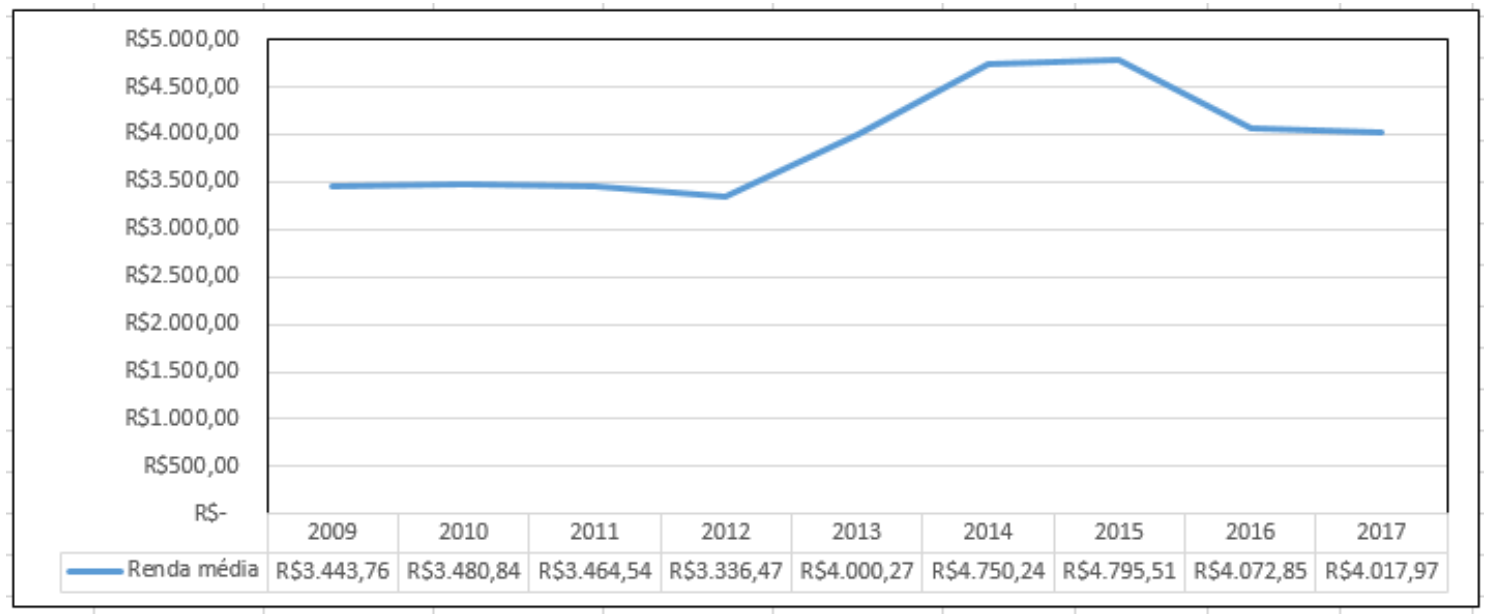

Fonte: BRASIL. CONAB (2015, 2016 e 2018). SUPAF/GECAF.

Em 2017, a renda média anual das mulheres no PAA foi $\mathrm{R} \$ 54,88$ ou $1,38 \%$ inferior a de 2016 (VIEGAS, 2018).

Ainda que se tenha falado da questão do gênero nos últimos anos, muito tem que se avançar para se conquistar a equidade entre homens e mulheres. Isso por que, “[...] trazer este tema para dentro do rural é algo bem mais complexo, pois o espaço do rural é marcado pela rígida divisão sexual do trabalho e pela posição subordinada das mulheres aos homens" (AZEVEDO; BARRETO; SANTOS, 2012, p. 4), mesmo que haja tentativas de mudanças, como por exemplo, na implementação do PAA.

\section{CONSIDERAÇÕES FINAIS}

Verificou-se no decorrer do artigo que o PAA tem se mostrado um importante canal de comercialização e uma relevante fonte de renda para os agricultores familiares.

Em suma, constatou-se que os municípios estudados possuem estrutura fundiária concentrada - o que é um reflexo de toda a Microrregião Geográfica de Presidente Prudente - ainda que se tenha estudado o município de Mirante do Paranapanema (SP) que é considerado "a capital da Reforma Agrária” por conta do seu expressivo número de

\footnotetext{
6 O fator "Renda das mulheres no PAA" não foi avaliado nos relatórios da CONAB referente aos anos de 2016 e 2017, por tal motivo, entramos em contato com a referida Companhia e tivemos os dados destes anos enviados pelo Sr. Gustavo Lund Viegas, gerente de acompanhamento e controle das ações da agricultura familiar (DF) da CONAB por meio do endereço eletrônico: < lianecarvalho11@yahoo.com.br>. Acesso em: 9 ago. 2018.

7 Os valores foram deflacionados por meio da Correção pelo Índice Geral de Preços (Fundação Getúlio Vargas) - IGP-DI (FGV) da Calculadora do Cidadão disponível no site do Banco Central do Brasil: <https://www3.bcb.gov.br/CALCIDADAO/publico/corrigirPorIndice.do?method=corrigirPorIndice $>$. Acesso em: 23 ago. 2018. No entanto, o ano de 2009 foi utilizado como ano base e, por isso, se considerou o valor nominal.
} 
|Eliane Regina Francisco da Silva | Rosangela Aparecida de Medeiros Hespanhol|

assentamentos rurais (35 no total). Ainda que apresentado um alto IDHM reconhece-se a necessidade de políticas públicas voltadas aos agricultores familiares.

Quanto à participação das mulheres na referida política pública, constatou-se que o programa permitiu que o trabalho desempenhado por elas passasse a ter maior visibilidade e isso resultou em melhorias das condições de vida dessas mulheres e das suas famílias.

$\mathrm{Na}$ escala nacional, identificou-se que no período de 2015 a 2017, o percentual de participação das mulheres no PAA foi ascendente, passando de 49 a 71\%. No entanto, não se pode precisar se o aumento da participação das mulheres está ligado à resolução $\mathrm{n}^{\circ} 44$ emitida pela SESAN - em que se evidencia o intuito de fomentar o acesso de mulheres ao PAA e onde se reconhece o Estado como principal agente no combate às desigualdades de gênero no espaço produtivo - ou se realmente se trata de um avanço em termos de divisão do trabalho no campo.

Por fim, a participação das mulheres mirantenses e rosanenses no PAA foi evidenciada não somente durante o processo produtivo, mas também no de comercialização, segundo os resultados obtidos na pesquisa de campo.

Cumpre lembrar que os valores auferidos com a participação das mulheres no PAA do recorte espacial analisado contribuem não somente para a aquisição de bens para o consumo próprio, mas também para a constituição da renda familiar como um todo.

$\mathrm{Na}$ opinião das agricultoras entrevistadas nos municípios de Mirante do Paranapanema e Rosana (SP), o PAA tem como pontos positivos, o aumento da renda, a criação de um canal de comercialização para os seus produtos, o pagamento seguro e regular e o incentivo e o reconhecimento do trabalho das mulheres no campo. Enquanto que os pontos negativos são: o valor da cota a ser entregue por produtor que era considerada baixa pelas entrevistadas, a fragilidade de muitas organizações sociais e a instabilidade política da gestão local.

Vale ressaltar que não há a priorização da continuidade do PAA por parte do governo federal atual, desse modo, a adequada alimentação dos beneficiários e o canal de comercialização dos agricultores familiares estão significativamente comprometidos.

\section{REFERÊNCIAS}

AZEVEDO, H. S.; BARRETO, F. O.; SANTOS, M. N. F. A participação de mulheres como critério de avaliação dos projetos do Programa de Aquisição de Alimentos. In: SEMINÁRIO INTERNACIONAL FAZENDO GÊNERO, 10., 2012, Florianópolis.
Anais...
Florianópolis,
2012.
Disponível
em: 
|As mulheres no Programa de Aquisição de Alimentos (PAA) nos municípios de Mirante do Paranapanema e Rosana (SP)|

|Eliane Regina Francisco da Silva | Rosangela Aparecida de Medeiros Hespanhol|

$<\underline{\text { http://www.fg2013.wwc2017.eventos.dype.com.br/resources/anais/20/1373326394 AR }}$ QUIVO Artigo Cod 7997477 HelenaSelmaAzevedo.pdf>. Acesso em: 24 jan. 2018.

BRASIL. Companhia Nacional de Abastecimento (CONAB). Ações da Conab-PAA. 2015. Disponível em: <http://www.conab.gov.br/conteudos.php? $\mathrm{a}=1629 \& \mathrm{t}=2>$. Acesso em: 23 fev. 2017.

BRASIL. Companhia Nacional de Abastecimento (CONAB). Programa de Aquisição de Alimentos - PAA: resultados das ações da CONAB em 2017. Compêndio de Estudos CONAB, v. 13, 2018. Disponível em: <https://www.conab.gov.br/agriculturafamiliar/execucao-do-paa>. Acesso em: 9 ago. 2018.

BRASIL. Ministério do Desenvolvimento Agrário (MDA). Políticas públicas para mulheres rurais no Brasil. Brasília: Diretoria de Políticas para Mulheres Rurais DPMR/MDA, $2017 . \quad$ Disponível em: $<\underline{\text { http://www.mda.gov.br/sitemda/sites/sitemda/files/ceazinepdf/POLITICAS PUBLIC }}$ AS PARA MULHERES RURAIS NO BRASIL.pdf>. Acesso em: 3 fev. 2018.

BRASIL. Ministério do Desenvolvimento Social e Combate a Fome (MDS). Brasil sai do mapa da fome das nações unidas, segundo FAO. Notícias MDS, set. 2014. Disponível em: < http://www.mds.gov.br/saladeimprensa/noticias/2014/setembro/brasil-sai-do-mapada-fomedas-nacoes-unidas-segundo-fao $>$. Acesso em: 30 mar. 2017.

BRASIL. Plataforma Atlas Brasil. Índice de Desenvolvimento Humano. Disponível em: < http://www.atlasbrasil.org.br>. Acesso em: 21 mar. 2018.

COUTINHO DE PAULA, L. A.; HESPANHOL, R. A. M. O PAA no assentamento São José em Presidente Prudente (SP): seus desdobramentos na vida das mulheres agricultoras. In: ENCONTRO NACIONAL DE GEOGRAFIA AGRÁRIA, 21., 2012, Uberlândia. Anais... "Territórios em disputa: Os desafios da Geografia Agrária nas contradições do desenvolvimento brasileiro". Uberlândia - MG: IG/UFU, 2012. Disponível em: <http://www.lagea.ig.ufu.br/xx1enga/anais enga 2012/eixos/1146 1.pdf>. Acesso em: 12 fev. 2018.

FERNANDES, B. M. Inserção sociopolítica da luta pela terra: ocupações de terra e assentamentos rurais no Pontal do Paranapanema - SP. In: BERGAMASCO, S. M. P. P.; AUBRÉE, M.; FERRANTE, V. L. S. B. (Org.). Dinâmicas familiar, produtiva e cultural nos assentamentos rurais de São Paulo. Campinas: Feagri/Unicamp; Uniara/Incra: Araraquara, 2003.

FREY, K. Políticas públicas: um debate conceitual e reflexões referentes à prática da análise de políticas públicas no Brasil. Planejamento e Políticas Públicas (IPEA), Brasília, n. 21, p. 211-259, 2000. Disponível em: <http://www.ipea.gov.br/ppp/index.php/PPP/article/view/89>. Acesso em: 16 set. 2019.

GOMES JÚNIOR, N. N.; ANDRADE, É. R. Uma discussão sobre a contribuição das mulheres na disputa por soberania alimentar. Porto Alegre: Revista Textos \& Contextos, v. 12, n. 2, p. 392-402, jul./dez. 2013.

IBGE - INSTITUTO BRASILEIRO DE GEOGRAFIA E ESTATÍSTICA. Censos agropecuários de 1995/96. Disponível em: 
|As mulheres no Programa de Aquisição de Alimentos (PAA) nos municípios de Mirante do Paranapanema e Rosana (SP)|

|Eliane Regina Francisco da Silva | Rosangela Aparecida de Medeiros Hespanhol|

< https://ww2.ibge.gov.br/home/estatistica/economia/agropecuaria/censoagro/1995 19 96/default.shtm >. Acesso em: 12 ago. 2018.

IBGE - INSTITUTO BRASILEIRO DE GEOGRAFIA E ESTATÍSTICA. Censos agropecuários de $2006 . \quad$ Disponível em: $<$ https://ww2.ibge.gov.br/home/estatistica/economia/agropecuaria/censoagro/2006/def ault.shtm>. Acesso em: 12 ago. 2018.

IBGE - INSTITUTO BRASILEIRO DE GEOGRAFIA E ESTATÍSITCA. Censos demográficos de $1991 . \quad$ Disponível em: $<$ https://www.ibge.gov.br/estatisticas/sociais/saude/9663-censo-demografico1991.html?edicao=9771\&t=sobre $>$. Acesso em: 10 jul. 2018.

IBGE - INSTITUTO BRASILEIRO DE GEOGRAFIA E ESTATÍSITCA. Censos demográficos de 2000 Disponível em: $<$ https://www.ibge.gov.br/estatisticas/sociais/saude/9663-censo-demografico2000.html?edicao=9771\&t=sobre $>$. Acesso em: 10 jul. 2018.

IBGE - INSTITUTO BRASILEIRO DE GEOGRAFIA E ESTATÍSITCA. Censos demográficos de 2010. Disponível em: $<$ https://www.ibge.gov.br/estatisticas/sociais/saude/9663-censo-demografico2010.html?edicao=9771\&t=sobre > . Acesso em: 10 jul. 2018.

IBGE - INSTITUTO BRASILEIRO DE GEOGRAFIA E ESTATÍSTICA. Diretoria de Pesquisas, Coordenação de Trabalho e Rendimento. Pesquisa Nacional por Amostra de Domicílios Contínua, 2018. Disponível em: $<$ https://oglobo.globo.com/sociedade/educacao/brasil-ainda-tem-118-milhoes-deanalfabetos-segundo-ibge-22211755>. Acesso em: 12 ago. 2018.

IZIDORO, L. T. Para além do espaço doméstico: o Programa de Aquisição de Alimentos e a visibilização do trabalho feminino nos assentamentos rurais de Presidente Venceslau - SP. 2015. 106 f. Monografia (Graduação em Geografia) - Faculdade de Ciências e Tecnologia, Universidade Estadual Paulista, Presidente Prudente, 2015.

MARIOTO, A. Programa de Aquisição de Alimentos (PAA) e o desenvolvimento territorial: um estudo comparativo entre os municípios de Euclides de Cunha Paulista - SP e Paranavaí - PR. 2013. 183 f. Dissertação (Mestrado de Geografia) - Faculdade de Ciências e Tecnologia, Universidade Estadual Paulista, Presidente Prudente, 2013.

PLANO MUNICIPAL DE DESENVOLVIMENTO RURAL SUSTENTÁVEL (PMDRS) DE MIRANTE DO PARANAPANEMA, 2010.

PLANO MUNICIPAL DE DESENVOLVIMENTO RURAL SUSTENTÁVEL (PMDRS) DE ROSANA, 2010.

RAMALHO, C. B. Impactos socioterritoriais dos assentamentos rurais no município de Mirante do Paranapanema - Região do Pontal do Paranapanema/SP. 2002. 156 f. Dissertação (Mestrado em Geografia) - Faculdade de Ciências e Tecnologia, Universidade Estadual Paulista, Presidente Prudente, 2002.

SANTOS, M. P. Mirante do Paranapanema: 50 anos de história. Mirante do Paranapanema, 2003. 1 CD ROM. 
|Eliane Regina Francisco da Silva | Rosangela Aparecida de Medeiros Hespanhol|

SAQUET, M. A. Abordagens e concepções de território. São Paulo: Expressão Popular, 2010.

SILVA, P. F. J. Cidades pequenas e indústria: contribuição para a análise da dinâmica econômica na Região de Presidente Prudente - SP. 2011. 285 f. Dissertação (Mestrado em Geografia) - Faculdade de Ciências e Tecnologia, Universidade Estadual Paulista, Presidente Prudente, 2011.

SOUZA, S. P. Assentamentos rurais e novas dinâmicas socioeconômicas: o caso dos municípios de Rosana, Euclides da Cunha Paulista e Teodoro Sampaio - SP. 2007. 193 f. Dissertação (Mestrado em Geografia) - Faculdade de Ciências e Tecnologia, Universidade Estadual Paulista, Presidente Prudente, 2007.

SOUZA, J. R. M. A política de aquisição de alimentos na mira do golpe. In: Revista Okara: Geografia em debate, João Pessoa, v. 12, n. 2, p. 664-677, 2018. Disponível em: < http://www.okara.ufpb.br>. Acesso em: 18 ago. 2018.

VELOSO, F. Políticas públicas no município de Junqueirópolis (SP): o PRONAF e o PAA. 2011. 249 f. Dissertação (Mestrado em Geografia) - Faculdade de Ciências e Tecnologia, Universidade Estadual Paulista, Presidente Prudente, 2011.

VIEGAS, G. L. Renda das mulheres no PAA nos anos de 2016 e 2017 [mensagem pessoal]. Mensagem recebida por <lianecarvalho11@yahoo.com.br> em: 9 ago. 2018. 